\title{
Reconstruction of patellar tendon following implantation of proximal tibia megaprosthesis for the treatment of post-traumatic septic bone defects
}

\author{
Giorgio M. Caloria , Emilio Luigi Mazza ${ }^{\mathrm{a}}$, Luca Vaientib, Simone Mazzola ${ }^{\mathrm{a}}$, Alessandra Colombo ${ }^{\mathrm{a}}$, Luca Galac, \\ Massimiliano Colombo ${ }^{\mathrm{a}, *}$ \\ ${ }^{a}$ Reparative Orthopaedic Surgery Department - ASST Pini-CTO, University of Milan, Italy \\ ${ }^{b}$ Department of Plastic and Reconstructive Surgery, I.R.C.C.S. Policlinico San Donato, University of Milan, Italy \\ ${ }^{c}$ Second division - ASST Pini-CTO, University of Milan, Italy
}

\section{K E Y W O R D S}

Patellar tendon reconstruction megaprosthesis

soft tissue coverage

\begin{abstract}
A B S T R A C T
Introduction: Latest advances made in joint replacement implants allows reconstruction of entire limbs. These special prostheses or megaprostheses were originally designed for the treatment of severe oncological bone loss. Nowadays, however, the indications and applications of these devices are expanding to other orthopaedic and trauma clinical conditions. Since 2008 we have implanted 152 megaprostheses in non-oncological conditions: 87 were implanted for post-traumatic failures aseptic/septic (represented by complex non-unions and critical size bone defects); 26 total femur, 52 distal femur and 9 proximal tibia. In this group of patients bone and soft tissues conditions are completely different compared to patients with oncological back ground. The presence of infection and previous surgeries can lead to adhesion, scar interference, muscular and tendon impairment and skin problems that lead to reduced function and severe joint stiffness. The purpose of this study is to evaluate the results of treatment of reconstruction of patellar tendon during implantation of proximal tibia megaprosthesis for the treatment of septic post traumatic critical bone defects.

Patients and methods: In this retrospective study, we evaluated 9 patients treated with proximal tibia megaprosthesis who underwent patellar tendon reconstruction. All patients presented a complete patellar tendon disruption at the time of prosthesis implantation. Procedures of reconstruction included a tendon-plasty of quadriceps and/or patellar tendons, a pie crusting of quadriceps fascia, a reinforcement of the apparatus with synthetic tendon graft substitutes (LARS) and a medial gastrocnemius muscular flap to reconstruct the extensor mechanism and obtain skin coverage when needed. The average follow up was 18 months (9-36). For each of the cases, we analysed the complications occurred regarding septic recurrence, patellar fracture, quadriceps and patellar tendon rupture and number of reinterventions. The clinical outcome was assessed by the WOMAC Score. Results: In all cases there was no infection recurrence or skin related problems. None of the patients require prosthesis revision due to loosening or device failure. No patellar fracture or quadriceps tendon failure was recorded.

One patient presented a rupture of the reconstructed patellar tendon due to a trauma incident 18 months after the implantation and he required revision surgery. From a clinical point of view the average WOMAC score was 62.4 at 1 month rising to 72.6 at 3 months, 78.2 at 6 months, 76.4 at 1 year and 74.8 at 18 months.

Conclusion: When proximal tibia megaprosthesis is implanted and there are soft tissue and patellar tendon deficiency, soft tissue reconstruction can be achieved by appropriate lengthening of the tendon and a gastrocnemius flap reinforced by LARS. Such an approach allows restoration of the extensor mechanism and coverage of the prosthesis in an area where skin problems are frequently very common.
\end{abstract}

ㄷ 2016 Elsevier Ltd. All rights reserved.
* Corresponding author at: Massimiliano Colombo, Reparative Orthopaedic Surgery Department - ASST Pini-CTO, University of Milan, Piazza Cardinal Ferrari 1, 20122 Milan, Italy. Tel.: +390258296904; Fax. +390258296905; Mobile: +393381687665.

E-mail address: maz.colombo@hotmail.it (Massimiliano Colombo).

\section{Introduction}

Critical bone defect of traumatic or prosthetic origin continue to be a complex problem for the orthopaedic surgeon. Patients not infrequently have undergone a number of previous procedures limiting the options of reconstruction or may possess a number of 
comorbidities which impair the healing potential of the affected extremity. The aetiology of critical bone defects include acute traumatic loss, extended bone resections performed to treat nonunion or underlying septic complications.

Although bone reconstruction techniques have been developed and refined over the years, their applications can still lead to long-term treatment and complications may occur leading to serious long-term impact on both the quality of life of the patient and on the welfare costs.

There are various reconstructive strategies to treat bone defects such as autograft and allogeneic bone grafting, bone transport, biological based therapies in the form of monotherapy [1] or polytherapy $[2,3]$, the use of standard prosthesis and/or megaprosthesis.

Lately, a classification system NUSS (Non Union Scoring System) was introduced allowing the evaluation of the risk factors and comorbidities of the patient, bone and other tissues, which can be used to obtain a prognosis and to provide guidance on surgical treatment $[4,5]$. Patients with a score higher than 75 points present very compromised general and local conditions and further reconstructive treatment is not recommended. The recommendations for this group of patients include primary amputation, arthrodesis or the implantation of a prosthesis. In patients who do not wish to consider primary amputation as a solution of their problem, our approach to provide a reasonable functional solution has been the replacement of all or part of the affected extremity with megaprosthesis. Our philosophy of substitution treatment can quickly restore function rather than chasing again unsuccessful attempts to reconstruction $[6,7]$.

In such cases, bone and soft tissues conditions are completely different from the routine oncological patient group. The quality of the knee extensor mechanism is very often in a critical condition particularly in post-traumatic septic patients who have undergone multiple surgeries. Tissue adhesion, scar interference, muscular and tendon impairment, soft tissue retractions, osteoporosis and skin problems lead to a reduced function of the knee, severe joint stiffness and also create adverse condition during the reconstructive step.

A specific complication that can lead to very poor results involves anterior tibial apophysis avulsion and partial tear or complete disruption of the patellar tendon. In such case, limitations exist intraoperative on how to restore the tendon loss and post-operatively how to manage the rehabilitation program of the patient. In addition, in cases where the entire proximal part of tibia is removed, reconstruction of the extensor apparatus must be reinserted directly into the prosthesis and adequate soft tissue must be present to cover to prosthetic component. In this study, we present our results of reconstruction of patellar tendon during implantation of proximal tibia megaprosthesis for the treatment of septic post traumatic critical bone defects.

\section{Patients and methods}

Between January 2008 and January 2016 we treated 152 non oncological patients with mega-prosthesis for large bone resections. The implants performed were: 54 proximal femurs, 52 distal femurs, 9 proximal tibias, 7 distal tibias, 26 total femurs, 4 arthrodesis for large resection of the knee. The implant used in all cases was the prosthesis Megasystem-C (Waldemar LINK, Germany). In this retrospective analysis we evaluated 9 patients treated with proximal tibia megaprosthesis who underwent patellar tendon reconstruction. All the patients presented a septic condition and were treated in two surgical steps (1st step: device removal + resection of septic bone and nonunion + implantation of antibiotic spacer; 2nd step: after an average period of 3 months: removal of the antibiotic spacer and implantation of definitive mega-prosthesis). The average follow up time was 18 months (9-36) since the second procedure. All patients presented a complete patellar tendon disruption at the second stage.

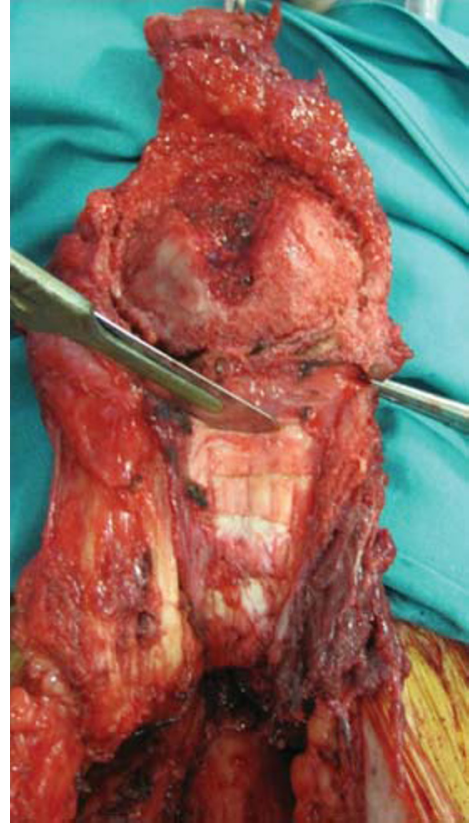

Fig. 1. Tendon-plasty for lengthening the quadriceps tendon.

\section{Techniques of reconstruction}

- Tendon-plasty of the quadriceps and/or patellar tendons to stretch the tendon fibres and enable functional reconstruction (9/9 patients) (Figure 1).

- Pie crusting of quadriceps fascia to lengthen it and enable functional reconstruction and future mobilization, thus reducing the strain on the new apparatus and limiting new rupture (7/9 patients) (Figure 2).

- Anchoring the apparatus reinforced by synthetic tendon graft substitutes (LARS) directly to the prosthetic element using an appropriate plate built for this purpose (9/9 patients) (Figure 3 ).

- Medial gastrocnemius muscular flap to reconstruct the extensor mechanism (9/9 patients) and obtain skin coverage if needed (5/9 patients) (Figure 4).

- Reinforcement of the patella through peripheral cerclage with nonabsorbable metal core wire in patients with severe osteoporosis and at high risk of fracture (3/9 patients).

All reconstructions were performed by a single operator and by the same team during this period. Patient follow-up was performed with

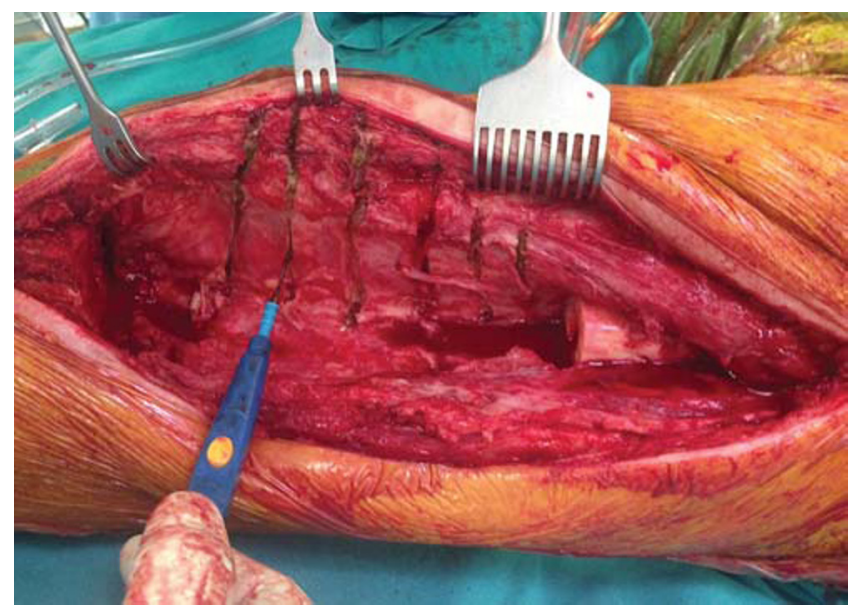

Fig. 2. Pie crusting of quadriceps fascia. 

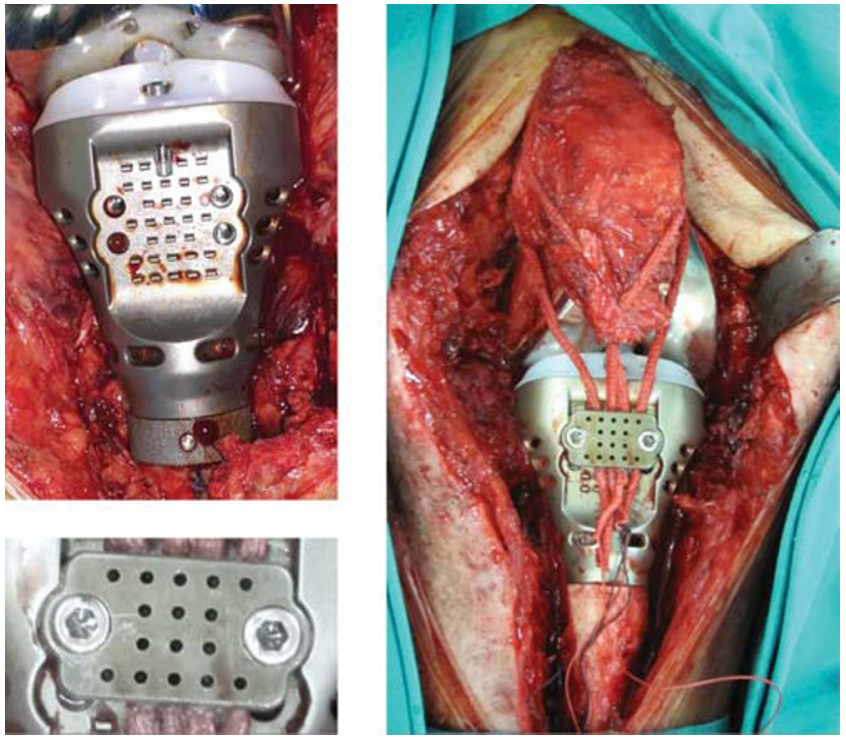

Fig. 3. Reinforcement of the patellar tendon using synthetic tendon graft substitutes (LARS) and tendon anchoring at the prosthetic component using dedicated plate.

clinical and radiographic evaluations at 45 days 3-6-12-18-24-36 months.

The mean age of patients was 68 years (43-89); 6 patients were male and 3 were female. The average NUSS score was 82 (76-92). Implants used were cemented with an antibiotic cement, the choice of the antibiotic cement was by the strain and sensitivity of the bacteria isolated during the first surgery. All patients were mobilized on the second postoperative day and prescribed an articulated brace locked in extension between 0 and $30^{\circ}$ of flexion for not less than 30 days. Subsequently, physiotherapy program was initiated focusing on muscle strengthening exercises and on improvement of active and passive range of motion of the knee. For each case, we analysed complications occurred regarding septic recurrence, patellar fracture, quadriceps and patellar tendon rupture, number of reinterventions. Clinical results were evaluated using the WOMAC Score.

\section{Results}

In all cases we had not infection recurrence or skin related problems. None of the patients require prosthesis revision due to loosening or device failure. No patellar fracture or quadriceps tendon failure was recorded. One patient presented a rupture of the reconstructed patellar tendon due to a trauma fall 18 months after the implantation procedure and necessitated revision surgery (Figure 5). The average WOMAC score was 62.4 at 1 month rising to 72.6 at 3 months, 78.2 at 6 months, 76.4 at 1 year, and 74.8 at 18 months.

\section{Discussion}

The treatment of non union with gaps and bone defects remains a clinical challenge [8-13]. When the location of the defect is in close proximity to the articular surface and particularly in the background of infection treatment options remain limited with the use of a megaprosthesis being one of them to restore function. This case scenario is commonly found in the proximal tibia where in addition to the affected bone that need to be replaced, ligament and soft tissue envelope reconstruction is essential for reducing the risk of failure and functional impairment.

Extensor mechanism disruption is a frequent source of postoperative morbidity. It is a quite rare entity $(0.7-2.7 \%)$, but most often presents in the setting of a megaprosthesis implantation due to multiple previous surgeries and infection [8]. Discontinuity in any of its components can lead to an extensor mechanism failure and render an otherwise perfectly good prosthesis useless. Hence there is a need to reconstruct a functional apparatus when it is completely absent.

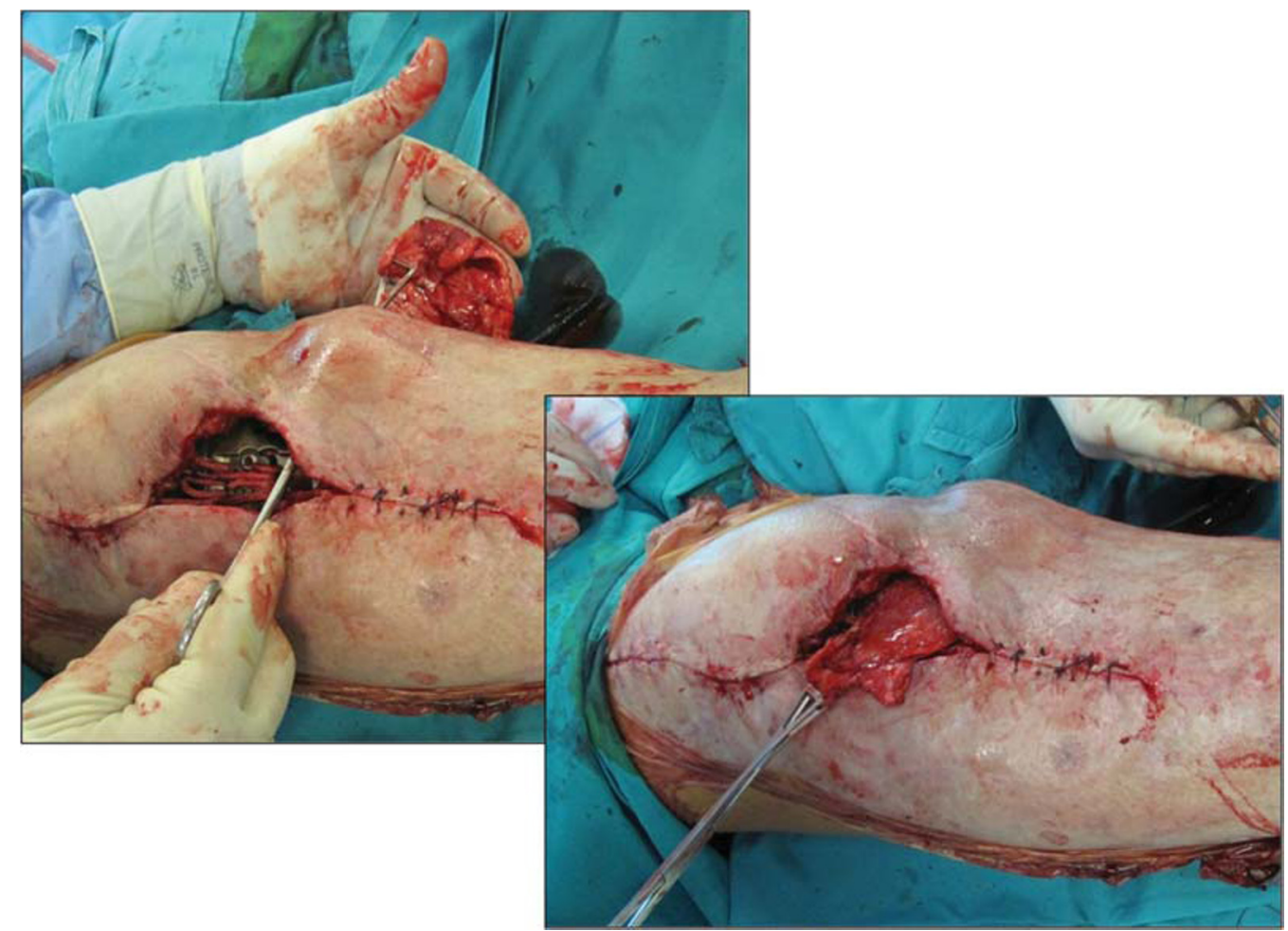

Fig. 4. Medial gastrocnemius muscular flap to reconstruct the extensor mechanism and obtain soft tissue coverage. 

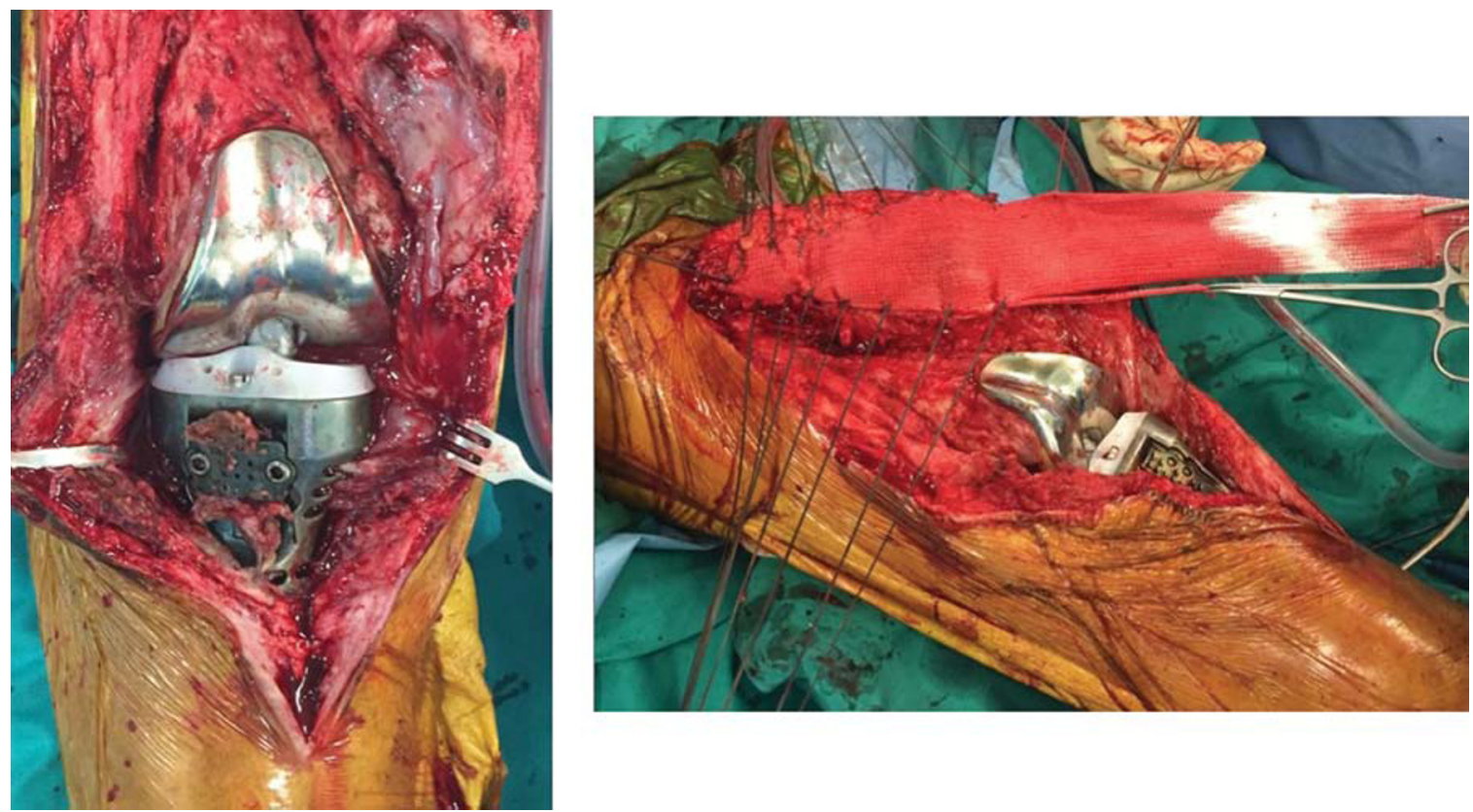

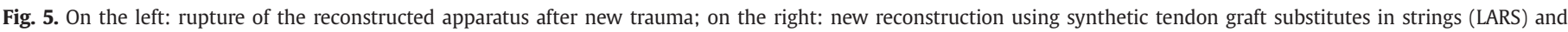
mesh (ARTELON).

The ideal surgical management of extensor mechanism disruption remains controversial. The treatment options for the repair include direct primary repair, or reconstruction with a synthetic ligament, autograft, or allograft tissue $[14,15]$. Various treatment options are available for managing these challenging issues, and recent advances in alternative techniques have yielded promising results.

The degree of mechanical compromise should always drive the surgeon towards a particular surgical treatment. The latter is determined by the amount of disruption ( patellar tendon, patella, or quadriceps tendon), degree of functional impairment (partial versus full tear), acute versus chronic nature of the disruption, availability of healthy tissue for either direct primary repair or augmentation, and the compliance of the patient [16]. Direct primary repair is a viable option in some cases and most often is a repair that involves patellar tendon ruptures. Quadriceps tendon tears should be carefully evaluated before planning a direct repair. A large review that studied exclusively quadriceps tendon ruptures showed a fairly high incidence of poor results after open surgical repair. But when facing a complete and chronic rupture a quadriceps turndown, allograft reconstruction or synthetic graft is probably the best option [17-24].

Acute avulsions of the patellar tendon from bone can be treated with sutures in the soft tissue and either drill holes in bone, staples or screws or suture anchors in the bone. In the mid-substance tear, usually end to end repair is the choice of treatment. Chronic patellar tendon tears, however, tend to be complicated by retraction or shortening of the extensor mechanism. This can make it difficult to get a tension free repair, which is essential to achieve adequate healing of the affected tissue. Autograft can be used as an augment to enhance the tensile strength of the repair or as tendon transfers to improve this substantial loss of function. In the first setting usually semitendinosus autograft is used; this technique requires a tendon harvest maintaining its distal attachment. The tendon is then passed through a transverse hole created in the inferior patella and then reattached distally into remaining soft tissue at the tendon origin. The gracilis tendon can also be harvested and attached to the semi-tendinosis for additional length if needed [21]. Allograft reconstruction is an alternative option that can restore active extension of the knee [22-24]. The main advantage of this technique is to avoid autologous harvesting, reducing the morbidity of the surgical procedure. Moreover, some studies show that biological integration is similar to autografts [25].
The options for allograft reconstruction include an en bloc extensor mechanism allograft (EMA, comprising quadriceps tendon, patella, patellar tendon, and tibial tubercle allograft) or an Achilles tendon bone block allograft (ATA) [26-29]. Although the original series of EMA showed good results $[21,22]$, some other series have shown that the rate of failure appears to be a critical issue $[23,30]$, especially following re-revisions [31]. Satisfactory experiences have been reported with the ATA by some authors $[8,32,33]$, with results comparable to EMA in terms of success [32]. The most comprehensive report on this technique is by Diaz-Ledezma et al. [34], where his study demonstrated a modest $58.6 \%$ success rate in 29 knees at a mean follow-up of 3.5 years. Although a clear advantage of an Achilles tendon allograft in the case of an isolated patellar tendon disruption is preservation of the native patella, our experience is that proximal fixation of the graft is more difficult. Allograft technique, however, is not without potential complications; the risk of recurrent extensor mechanism disruption is evaluated between $5 \%$ and $100 \%[8,28,30,32]$. Recurrence is mostly seen after unsuccessful ATA fixation or more frequently proximal fixation in the quadriceps tendon. Another causative factor supported by some authors is gradual elongation of the soft tissues to explain this complication [30]. Secondary disruption can be prevented by a stable primary fixation as well as by immobilization in extension of at least 6 to 8 weeks [23]. A postoperative extensor lag seen during active extension is a major prognostic feature, the mean is $15^{\circ}$ [32] but has been found to reach $59^{\circ}$ [30]. An extensor lag can be partially prevented by tensioning the graft and by keeping the limb in full extension while securing the quadriceps [24]. Concerns with the use of allograft include tissue availability, cost, immune reaction, and disease transmission [35].

Synthetic grafts are another option for EM reconstruction. One major advantage of this synthetic material over allograft is the apparent maintenance of tensile strength and avoidance of graft elongation with time.

The use of a synthetic graft for an extensor mechanism reconstruction includes LARS [36], Leeds-Keio ligament [37], Trevia tube [38] and the mesh $[39,40]$. Dominkus et al. reported the use of LARS for the reconstruction after tumor resection, and the mean degree of the extension lag among the patients who had a resection of the proximal tibia was $25^{\circ}$ (range, 0-90) [29]. Browne and Hannsen [40] reported the use of the mesh for extensor reconstruction in 13 conventional TKAs 
and the mean extension lag (except cases of graft failure) measured $2.8^{\circ}$. Woven monofilament mesh can provide a framework for ingrowth of host tissue, with resultant orderly collagen formation that resembles normal ligament tissue [41]. The heavy-weight mesh also provides a good substrate for immediate suture fixation and in augmenting the often friable and compromised host tissue. Reconstruction with synthetic mesh eliminates the potential for disease transmission that is potentially associated with allograft implantation. Although the monofilament mesh is a foreign body, it has been shown to be unlikely to act as a nidus for microbial growth and may be beneficial as compared with the use of natural material such as collagen, which can serve as a potential binding site for bacteria [42-44]. Several studies showed no decrease in tensile strength of the mesh and biomechanical superiority over grafts [40,45-49].

A salvage technique that can be used for both reconstruction of the extensor mechanism and the skin coverage is a medial gastrocnemius muscle flap. This option has been described for combined tissue loss during revision knee arthroplasty or tumour surgery [48-52]. The medial gastrocnemius flap is a standard technique for soft tissue coverage and is reportedly safe and reliable with low donor site morbidity. Malawer et al. was the first that described medial gastrocnemius reconstruction of the extensor mechanism in four tumour patients with knee endoprosthesis [50]. Similarly, several authors $[15,48,49,51]$ have reported very good results using this flap after patellar or quadriceps tendon loss during complicated knee arthroplasty. However, in some cases gastrocnemius flaps may be insufficient to close defects of the lower portion of the capsule of the knee and are never adequate for defects involving the quadriceps tendon and rectus femoris muscle [51,53]. In this case scenario, the latissimus dorsi free flap [25], vastus medialis and lateralis flap, reversed gracilis pedicle flap [37], distally based vastus lateralis flap [8], rectus abdominus free flap [13], perforator flaps [24,31], and neurofasciocutaneous flaps [38] all have the potential to close large anterior defects but are technically demanding and require a plastic surgeon assistance. So local muscle and tendon transfer is a common practice to overcome diminished knee function.

This study is not without limitations, the main one being its retrospective nature and the small number of cases. However, extensor mechanism disruption is a rare and not predictable complication; a retrospective approach seems unavoidable in studying this difficult problem.

In conclusion, we believe, that the use of allograft is not the safest option in patients affected by post-traumatic and periprosthetic bone defects especially in a previous septic environment. Infections are the main cause of failure after prosthetic revision as revealed by recent studies with a risk that may be 10 -fold higher than primary procedures $[54,55]$. We recommend the use of synthetic materials to reinforce the apparatus, when a direct repair is not possible. When proximal tibia megaprosthesis is implanted we suggest to prepare the soft tissues by an appropriate lengthening and to perform a gastrocnemius flap reinforced by synthetic tendon graft substitutes (LARS) in order to restore the extensor apparatus and to cover the prosthesis in an area where skin problems are always very common.

\section{Conflict of interest}

None of the authors has conflicts of interest or source of funding to disclose.

\section{References}

[1] Calori GM, Colombo M, Mazza E, Ripamonti C, Mazzola S, Marelli N, et al. Monotherapy vs polytherapy in the treatment of forearm non unions and bone defects. Injury 2013;44 (Suppl 1):S63-9.

[2] Calori GM, Mazza E, Colombo M, Ripamonti C, Tagliabue L. Treatment of long bone non unions with polytherapy: indications and clinical results. Injury 2011;42:587-90.
[3] Calori GM, Colombo M, Ripamonti C, Bucci M, Fadigati P, Mazza E, et al. Polytherapy in bone regeneration: clinical applications and preliminary considerations. Int J Immunopathol Pharmacol 2011;24(1 Suppl 2): 85-89.

[4] Calori GM, Phillips M, Jeetle S, Tagliabue L, Giannoudis PV. Classification of non-union: need for a new scoring system? Injury 2008;39(Suppl 2):S59-63.

[5] Calori GM, Colombo M, Mazza EL, Mazzola S, Malagoli E, Marelli N, et al. Validation of the Non-Union Scoring System in 300 long bone non-unions. Injury 2014;45(Suppl 6): S93-7.

[6] Calori GM, Colombo M, Ripamonti C, Malagoli E, Mazza E, Fadigati P, et al. Megaprosthesis in large bone defects: opportunity or chimaera? Injury 2014;45:388-93.

[7] Calori GM, Colombo M, Malagoli E, Mazzola S, Bucci M, Mazza E. Megaprosthesis in posttraumatic and periprosthetic large bone defects: issues to consider. Injury 2014;45(Suppl 6):S105-10.

[8] Giannoudis PV, Calori GM, Bégué T, Schmidmaier G. Tissue loss and bone repair: Time to develop an international strategy? Injury 2015;46(Suppl 8):S1-2.

[9] Giannoudis PV. Treatment of bone defects: Bone transport or the induced membrane technique? Injury 2016;47:291-2.

[10] Watanabe Y, Harada N, Sato K, Abe S, Yamanaka K, Matushita T. Stem cell therapy: is there a future for reconstruction of large bone defects? Injury 2016;47(Suppl 1):S47-51.

[11] Giannoudis PV, Gudipati S, Harwood P, Kanakaris NK. Long bone non-unions treated with the diamond concept: a case series of 64 patients. Injury 2015;46(Suppl 8): S48-54.

[12] Shanmuganathan R, Chandra Mohan AK, Agraharam D, Perumal R, Jayaramaraju D, Kulkarni S. Successful reimplantation of extruded long bone segments in open fractures of lower limb-a report of 3 cases. Injury 2015;46:1389-92.

[13] Campanacci DA, Puccini S, Caff G, Beltrami G, Piccioli A, Innocenti M, et al. Vascularised fibular grafts as a salvage procedure in failed intercalary reconstructions after bone tumour resection of the femur. Injury 2014;45:399-404.

[14] Crossett LS, Sinha RK, Sechriest VF, Rubash HE. Reconstruction of a ruptured patellar tendon with achilles tendon allograft following total knee arthroplasty. J Bone Joint Surg Am 2002;84-A:1354-61.

[15] Lynch AF, Rorabeck CH, Bourne RB. Extensor mechanism complications following total knee arthroplasty. The Journal of Arthroplasty 1987;2:135-40.

[16] Schoderbek RJ, Jr., Brown TE, Mulhall KJ, Mounasamy V, Iorio R, Krackow KA, et al. Extensor mechanism disruption after total knee arthroplasty. Clin Orthop Rel Res 2006;446:176-85.

[17] Cooney WPt, Sierra RJ, Trousdale RT, Pagnano MW. Revision total knees done for extensor problems frequently require reoperation. Clin Orthop Rel Res 2005;440:117-21.

[18] Park SS, Kubiak EN, Wasserman B, Sathappan SS, Di Cesare PE. Management of extensor mechanism disruptions occurring after total knee arthroplasty. Am J Orthop (Belle Mead NJ) 2005;34:365-72.

[19] Dobbs RE, Hanssen AD, Lewallen DG, Pagnano MW. Quadriceps tendon rupture after total knee arthroplasty. Prevalence, complications, and outcomes. J Bone Joint Surg Am 2005;87:37-45.

[20] Rosenberg AG. Management of extensor mechanism rupture after TKA. J Bone Joint Surg Br 2012;94(11 Suppl A):116-9.

[21] Cadambi A, Engh GA. Use of a semitendinosus tendon autogenous graft for rupture of the patellar ligament after total knee arthroplasty. A report of seven cases. J Bone Joint Surg Am 1992;74:974-9.

[22] Malhotra R, Garg B, Logani V, Bhan S. Management of extensor mechanism deficit as a consequence of patellar tendon loss in total knee arthroplasty: a new surgical technique.J Arthroplasty 2008;23:1146-51.

[23] Burnett RS, Berger RA, Paprosky WG, Della Valle CJ, Jacobs JJ, Rosenberg AG. Extensor mechanism allograft reconstruction after total knee arthroplasty. A comparison of two techniques. J Bone Joint Surg Am 2004;86-a:2694-9.

[24] Murgier J, Boisrenoult P, Pujol N, Beranger JS, Tardy N, Steltzlen C, et al. Knee extensor mechanism allograft reconstruction following chronic disruption. Orthop Traumatol Surg Res 2015;101:867-70.

[25] Robertson A, Nutton RW, Keating JF. Current trends in the use of tendon allografts in orthopaedic surgery. J Bone Joint Surg Br 2006;88:988-92.

[26] Springer BD, Della Valle CJ. Extensor mechanism allograft reconstruction after total knee arthroplasty. J Arthroplasty 2008;23(7 Suppl):35-8.

[27] Parker DA, Dunbar MJ, Rorabeck CH. Extensor mechanism failure associated with total knee arthroplasty: prevention and management.J Am Acad Orthop Surg 2003;11:238-47.

[28] Nazarian DG, Booth RE, Jr. Extensor mechanism allografts in total knee arthroplasty. Clin Orthop Relat Res 1999;367:123-9.

[29] Emerson RH, Jr., Head WC, Malinin TI. Reconstruction of patellar tendon rupture after total knee arthroplasty with an extensor mechanism allograft. Clin Orthop Relat Res 1990;260:154-61.

[30] Leopold SS, Greidanus N, Paprosky WG, Berger RA, Rosenberg AG. High rate of failure of allograft reconstruction of the extensor mechanism after total knee arthroplasty. J Bone Joint Surg Am 1999;81:1574-9.

[31] Lewullis GE, Jasko JG, Booth Iii RE, Lonner JH. Revision extensor mechanism allografting after total knee arthroplasty. Am J Orthop (Belle Mead NJ) 2010;39:539-42.

[32] Burnett RS, Butler RA, Barrack RL. Extensor mechanism allograft reconstruction in TKA at a mean of 56 months. Clin Orthop Rel Res 2006;452:159-65.

[33] Barrack RL, Stanley T, Allen Butler R. Treating extensor mechanism disruption after total knee arthroplasty. Clin Orthop Rel Res 2003;416:98-104.

[34] Diaz-Ledezma C, Orozco FR, Delasotta LA, Lichstein PM, Post ZD, Ong AC. Extensor mechanism reconstruction with achilles tendon allograft in TKA: results of an abbreviate rehabilitation protocol. J Arthroplasty 2014;29(6):1211-5. 
[35] Eastlund T. Bacterial infection transmitted by human tissue allograft transplantation. Cell Tissue Bank 2006;7:147-66.

[36] Dominkus M, Sabeti M, Toma C, Abdolvahab F, Trieb K, Kotz RI. Reconstructing the extensor apparatus with a new polyester ligament. Clin Orthop Rel Res 2006;453:328-34.

[37] Fujikawa K, Ohtani T, Matsumoto H, Seedhom BB. Reconstruction of the extensor apparatus of the knee with the Leeds-Keio ligament. J Bone Joint Surg Br 1994;76:200-3.

[38] Gosheger G, Hillmann A, Lindner N, Rodl R, Hoffmann C, Burger H, et al. Soft tissue reconstruction of megaprostheses using a trevira tube. Clin Orthop Rel Res 2001;393:264-71.

[39] Ichikawa J, Matsumoto S, Shimoji T, Ae K, Tanizawa T, Gokita T. A new technique using mesh for extensor reconstruction after proximal tibial resection. Knee 2015;22:659-63.

[40] Browne JA, Hanssen AD. Reconstruction of patellar tendon disruption after total knee arthroplasty: results of a new technique utilizing synthetic mesh. J Bone Joint Surg Am 2011;93:1137-43.

[41] Hosey G, Kowalchick E, Tesoro D, Balazsy J, Klocek J, Pederson B, et al. Comparison of the mechanical and histologic properties of Achilles tendons in New Zealand white rabbits secondarily repaired with Marlex mesh. J Foot Surg 1991;30:214-33.

[42] Bhende S, Barbolt T, Rothenburger S, Piccoli L. Infection potentiation study of synthetic and naturally derived surgical mesh in mice. Surg Infect (Larchmt) 2007;8:405-14.

[43] Merritt K, Hitchins VM, Neale AR. Tissue colonization from implantable biomaterials with low numbers of bacteria. J Biomed Mater Res 1999;44:261-5.

[44] Mascari LM, Ross JM. Quantification of staphylococcal-collagen binding interactions in whole blood by use of a confocal microscopy shear-adhesion assay. J Infect Dis 2003;188:98-107.

[45] Winston LA, Terry AF, Jardine JH, Parrish FF. The result of replacement of partial or total collateral ligaments with Marlex mesh in the knees of dogs. Clin Orthop Rel Res 1978; 137:287-90.
[46] Dora CD, Dimarco DS, Zobitz ME, Elliott DS. Time dependent variations in biomechanical properties of cadaveric fascia, porcine dermis, porcine small intestine submucosa, polypropylene mesh and autologous fascia in the rabbit model: implications for sling surgery. J Urol 2004;171:1970-3.

[47] Boukerrou M, Boulanger L, Rubod C, Lambaudie E, Dubois P, Cosson M. Study of the biomechanical properties of synthetic mesh implanted in vivo. Eur J Obstet Gynecol Reprod Biol 2007;134:262-7.

[48] Busfield BT, Huffman GR, Nahai F, Hoffman W, Ries MD. Extended medial gastrocnemius rotational flap for treatment of chronic knee extensor mechanism deficiency in patients with and without total knee arthroplasty. Clin Orthop Rel Res 2004;428:190-7.

[49] Jaureguito JW, Dubois CM, Smith SR, Gottlieb LJ, Finn HA. Medial gastrocnemius transposition flap for the treatment of disruption of the extensor mechanism after total knee arthroplasty. J Bone Joint Surg Am 1997;79:866-73.

[50] Malawer MM, McHale KA. Limb-sparing surgery for high-grade malignant tumors of the proximal tibia. Surgical technique and a method of extensor mechanism reconstruction. Clin Orthop Rel Res 1989;239:231-48.

[51] Ries MD, Bozic KJ. Medial gastrocnemius flap coverage for treatment of skin necrosis after total knee arthroplasty. Clin Orthop Rel Res 2006;446:186-92.

[52] Rhomberg M, Schwabegger AH, Ninkovic M, Bauer T, Ninkovic M. Gastrocnemius myotendinous flap for patellar or quadriceps tendon repair, or both. Clin Orthop Rel Res 2000;377:152-60.

[53] Auregan JC, Begue T, Tomeno B, Masquelet AC. Distally-based vastus lateralis muscle flap: a salvage alternative to address complex soft tissue defects around the knee. Orthop Traumatol Surg Res 2010;96:180-4.

[54] Mortazavi SM, Molligan J, Austin MS, Purtill JJ, Hozack WJ, Parvizi J. Failure following revision total knee arthroplasty: infection is the major cause. Int Orthop 2011;35:115764.

[55] Mortazavi SM, Schwartzenberger J, Austin MS, Purtill JJ, Parvizi J. Revision total knee arthroplasty infection: incidence and predictors. Clin Orthop Rel Res 2010;468:2052-9. 